\title{
Laboreal
}

Volume $12 \mathrm{~N}^{\circ} 1$ | 2016

Os Equipamentos de Proteção Individual (EPI):

protetores, mas nem sempre

\section{Conceção organizacional: para intervenções capacitantes}

Diseño organizacional: para intervenciones "capacitantes"

Conception organisationnelle: pour des interventions capacitantes

Organisational conception: for empowering interventions

Justine Arnoud

\section{CpenEdition}

Journals

Edição electrónica

URL: http://journals.openedition.org/laboreal/3346

DOI: $10.4000 /$ laboreal.3346

ISSN: 1646-5237

Editora

Universidade do Porto

Refêrencia eletrónica

Justine Arnoud, "Conceção organizacional: para intervenções capacitantes », Laboreal [Online] Volume $12 \mathrm{~N}^{0} 1$ | 2016, posto online no dia 01 julho 2016, consultado o 24 setembro 2020. URL http://journals.openedition.org/laboreal/3346 ; DOI : https://doi.org/10.4000/laboreal.3346

Este documento foi criado de forma automática no dia 24 setembro 2020.

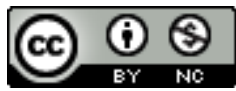

Laboreal está licenciado com uma Licença Creative Commons - Atribuição-NãoComercial 4.0 Internacional. 


\title{
Conceção organizacional: para intervenções capacitantes
}

\author{
Diseño organizacional: para intervenciones "capacitantes" \\ Conception organisationnelle : pour des interventions capacitantes \\ Organisational conception: for empowering interventions
}

Justine Arnoud

\section{REFERÊNCIA}

Arnoud, J. (2013). Concepção organizacional: para intervenções capacitantes. Tese de doutorado em Ergonomia. Centre de Recherche sur le Travail et le Développement. Paris : Conservatoire National des Arts et Métiers.

\section{NOTA DO EDITOR}

http://dx.doi.org/10.15667/laborealxii0116ja

Manuscrito recebido em: outubro/2015

Aceite após peritagem: dezembro/2015

\section{Introdução: a questão da organização}

1 Esta tese de ergonomia se inscreve no campo da organização. As novas formas de organização e o crescimento das atividades de serviço levantam novos desafios na disciplina. As demandas formuladas aos ergonomistas - no nosso caso o acompanhamento de uma mudança organizacional - convidam a investigar o objeto "organização" e as modalidades de intervenção sobre este objeto. Um diálogo entre ciências da atividade e ciências da organização e, então, aberto. Algumas questões aparecem: como apreender a organização? Sobre quais pontos a intervenção pode agir 
para contribuir à emergência de organizações mais favoráveis aos indivíduos e aos coletivos?

2 A contribuição histórica da ergonomia aos saberes de concepção facilita a reflexão em torno da concepção da organização - compreendida aqui como uma articulação entre "duas faces", a organização formal e a organização viva (Daniellou, 1999; Petit, Dugué \& Daniellou, 2011). Estrutura organizacional e ação dos atores alimentam assim trocas permanentes: "a estrutura representa simplesmente a cristalização passageira da atividade social, assim como a estrutura de um momento determina parcialmente esta atividade social" (Daniellou, 1999, p. 530, tradução livre).

3 A tese defendida é que a organização deve ser concebida ou re-concebida sob o ângulo do desenvolvimento. O desenvolvimento em questão é oriundo dos trabalhos com predominância econômica e em estreita relação com a abordagem das capabilidades (Sen, 1997). Assim, é mobilizado o projeto da Ergonomia Construtiva onde "o objetivo da ergonomia deve ser o desenvolvimento. (...) Desenvolvimento de indivíduos e das organizações" (Falzon, 2014, p. vii, tradução livre).

\section{Do ambiente capacitante às organizações capacitantes: um quadro teórico centrado no desenvolvimento}

4 A abordagem das capabilidades (Sen, 1997) é o pano de fundo do projeto da Ergonomia Construtiva. As "capabilidades" designam o conjunto de funcionamentos humanos disponíveis ao indivíduo, quer ele faça uso ou não, ou seja, é a real liberdade de escolha que cada um dispõe permitindo assim um desenvolvimento pessoal. Transpondo esse pensamento à organização (Arnoud \& Falzon, 2012), essa noção conduz a perspetivar a concepção organizacional como uma ajuda visando estruturar a organização em dois sentidos:

- a organização favorece as capabilidades;

- e permite a reinvenção de seu funcionamento pelos atores, conduzindo a um equilíbrio "provisório".

5 A questão de pesquisa é a seguinte: como conceber organizações que permitam às pessoas e aos coletivos ter êxito, se desenvolver e reiventar, se necessário, o quadro de suas ações afim de encontrar o melhor compromisso possível entre objetivos de bemestar e de performance?

6 A literatura no domínio da concepção nos fornece primeiras hipóteses. A concepção de sistemas adaptados não é suficiente. A implementação de um "ambiente capacitante" (Falzon, 2014), não deletério, não excludente e permitindo às pessoas o sucesso e o aprendizado também não pode ser a única finalidade a se buscar. A ação deve ser pensada de tal modo que favoreça a implementação, a longo prazo, de sistemas adaptáveis. Neste sentido, uma "organização capacitante" foi definida como sendo esta que permite a implementação de ambientes capacitantes adaptáveis e perenes. Três dimensões foram determinadas (Arnoud, 2013): uma organização-instrumento que possibilita a adaptação na sua utilização, favorável aos debates e às confrontações de pontos de vista e propícia ao desenvolvimento da atividade coletiva comum (práticas similares) e conjunta (práticas diferentes e complementares). Uma atenção particular é dada à análise desta última forma de atividade coletiva que permite ultrapassar o foco 
no posto de trabalho ou na situação de trabalho e apreender o "objeto" organização. Com efeito, a intervenção conjunta de atores múltiplos constitui de fato uma organização (Lorino, 2007).

\section{Uma metodologia fundada sobre a dinamização da organização}

7 A pesquisa foi desenvolvida entre 2010 e 2013 em uma multinacional francesa especializada em serviços relativos ao meio-ambiente. Ela ocorreu durante a implementação de Centros de Serviços Partilhados (CSP), estruturas definidas para a coordenação e partilha das funções de pagamento do pessoal de todas as entidades francesas do Grupo empresarial estudado. Uma metodologia de pesquisa e de experimentação foi definida com o intuito de conceber ambientes capacitantes e, a longo prazo, organizações capacitantes.

8 Neste sentido, e com o objetivo de focar o objeto "organização", a análise da atividade não foi conduzida unicamente com os trabalhadores gestionários das entidades de pagamento do pessoal. A análise foi realizada com vários atores do "processo pagamento" (os gestionários nos CSP e os seus « correspondentes» nas entidades), a quem é demandado de fazer coisas diferentes mas de maneira coordenada. Os correspondentes são assistentes de gestão repartidos nas diferentes entidades do grupo e têm por objetivo recolher todas as informações úteis para realizar o pagamento do pessoal. Essas informações são introduzidas em um software e tratadas pelos gestores do CSP (afastados geograficamente das entidades) encarregados de estabelecer, para várias entidades, as fichas de pagamento e realizar a transferência de salários. Uma relação cliente-fornecedor interna é formalizada através de um contrato que determina as necessidades e as obrigações das duas partes. A correspondência por meio escrito é prescrita com o intuito de identificar mais facilmente o não respeito das regras do contrato.

A metodologia adotada compreende três etapas:

10 Etapa 1 : Análise da situação atual e das tentativas de reconcepção no uso

11 Esta primeira etapa consistiu em analisar a situação atual, identificar as questões não resolvidas pela organização e caracterizar os determinantes das contradições às quais a atividade se confronta. Essa etapa "clássica" se concentrou mais especificamente em identificar os recursos disponíveis antes e depois da mudança organizacional e os fatores de conversão desses recursos em capabilidades maiores, quando relacionadas ao projeto de operacionalização da abordagem das capabilidades. Essa fase se interessou igualmente à maneira como os atores tentaram reconceber a organização "no uso" (Béguin, 2008) e analisar se essas tentativas modificaram ou não a estrutura organizacional.

- Etapa 2 : A co-análise construtiva das práticas

13 A segunda etapa teve por objetivo testar in situ, a partir das práticas observadas e do que pretendiam os atores, um método de desenvolvimento: a co-análise construtiva das práticas (Arnoud \& Falzon, 2014). Visitas nos locais de trabalho foram organizadas a fim de convidar os gestores e os correspondentes a observarem a atividade do seu parceiro. A atividade "aqui e agora" constituiu assim um objeto de diálogos, facilitando a prática 
reflexiva sobre a atividade coletiva conjunta assim como a transformação de regras e práticas.

A longo prazo, uma terceira etapa da pesquisa deverá ser realizada, permitindo tanto questionar a estrutura atual criticada e considerada inadaptada pelos atores quanto conduzir a implementação de uma organização capacitante capaz de se questionar no seu conjunto.

A metodologia realizada é ilustrada no esquema abaixo (Figura 1)

Figura 1. Metodologia centrada no desenvolvimento

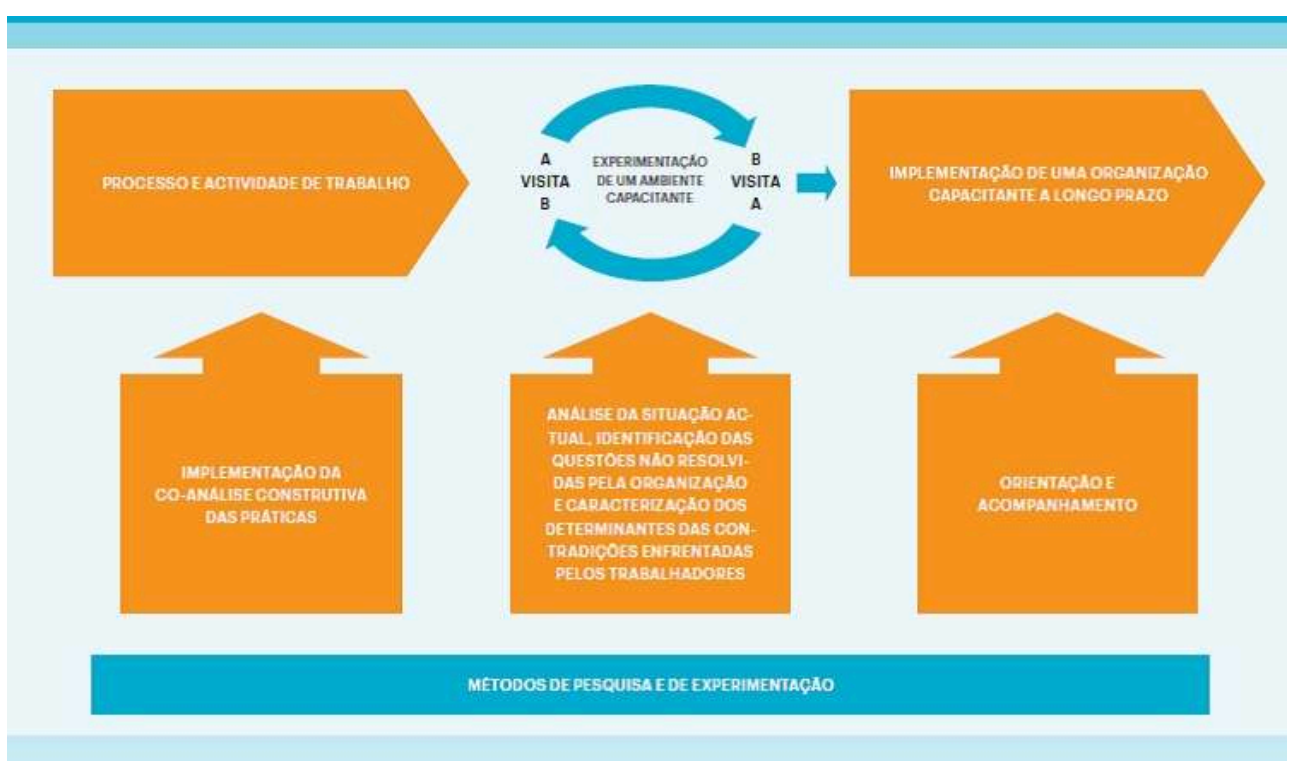

\section{Resultados principais}

17 De acordo com as três etapas metodológicas apresentadas acima, os principais resultados da pesquisa serão aqui expostos.

\subsection{Entraves ao desenvolvimento e identificação de numerosas tentativas de reconcepção no uso}

Considerando a mudança organizacional, é importante notar que a estrutura organizacional "CSP" foi pensada por pessoas da administração e imposta aos atores. Somente os aspectos técnicos foram discutidos com os últimos, em detrimento das dimensões processuais e relacionais da atividade de pagamento do pessoal. As tarefas foram segmentadas e um contrato de serviço foi elaborado. A primeira etapa da metodologia colocou em evidência uma forte diminuição das oportunidades de escolha, do raio de ação, e das possibilidades efetivas de realizar um trabalho de qualidade quando comparadas à situação antes da mudança (situação observada durante a intervenção). Utilizando a terminologia de Sen (1997), os recursos tiveram tendência a diminuir assim como suas possibilidades de conversão em capabilidades maiores. De maneira mais específica, os atores se sentiam incomodados no que se refere ao 
desenvolvimento da atividade coletiva conjunta. Os gestores exprimiam forte satisfação em trabalhar nesses CSP e os correspondentes das entidades se questionavam quanto a necessidade dessa nova organização. Os retornos reflexivos sobre o processo não eram totalmente partilhados e várias dissonâncias - diferenças constatadas com relação a realidades supostas - foram reveladas. No entanto, os operadores não se mostraram passivos diante da mudança de organização e tentaram facilitar a atividade coletiva permitindo assim a produção de um pagamento de qualidade. Por exemplo, apesar de serem proibidos, os atores do processo pagamento se telefonavam mutuamente e tentavam se ver pessoalmente, mesmo estando longe geograficamente, afim de "trabalhar melhor juntos". Essas tentativas são interpretadas como sinais de dificuldades importantes sentidas pelos trabalhadores. Através desses desvios, os trabalhadores do processo de pagamento tentavam reencontrar as margens de manobras e a autonomia perdidas, transformando os colegas de trabalho em recursos para a ação.

\subsection{A co-análise construtiva das práticas: uma ajuda para o retorno reflexivo sobre a atividade coletiva}

Afim de incentivar essas práticas e o retorno reflexivo sobre a atividade coletiva conjunta, uma experimentação foi realizada. Com base nas tentativas e no que pretendiam os trabalhadores do processo, um método chamado co-análise construtiva das práticas foi desenvolvido. Cada ator do processo foi convidado a observar seu parceiro (gestores ou correspondentes, com funções e competências complementares) em momentos chave da atividade, onde inúmeras interações e dificuldades foram observadas na etapa 1. Cada trabalhador verbalizava sua atividade ao seu parceiro. Esta reificação do trabalho produziu efeitos permitindo uma melhor compreensão mútua e partilha de experiências. O parceiro-observador poderia interromper a verbalização caso ele quisesse. A rememoração das dificuldades ou as surpresas ocasionadas durante a observação conduziram a um certo número de perguntas que tinham por finalidade esclarecer essa atividade coletiva, ou até mesmo modificá-la. A originalidade do dispositivo era o fato de confrontar cada um à atividade do seu parceiro em situação $\mathrm{e}$ não por intermédio de traços da atividade. Quatro binômios participaram do dispositivo. 0 pesquisador recolhia os dados sem interferir nas discussões. Entrevistas posteriores com os trabalhadores complementaram os dados e visavam verificar os efeitos do método nas atividades cotidianas. $O$ tratamento de dados permitiu identificar que na fase pós-experiência cada ator analisava sua atividade levando em conta a atividade de seu parceiro, o que visivelmente conduziu a mudanças de práticas afim de facilitar o trabalho do outro. Em alguns casos os atores buscavam juntos renegociar as regras e os modos de funcionamento da atividade coletiva conjunta. A organização foi assim questionada através dos usos e transformações perspetivadas pelos atores.

\subsection{Perenidade do dispositivo e dificuldades de uma reativação global da organização}

Os questionamentos oriundos desse trabalho deveriam ter sido integrados no âmbito dos espaços de discussão (Detchessahar, 2001) numa terceira etapa, mobilizando equipes e gestores afim de reinterrogar o contexto organizacional e encontrar soluções 
aceitáveis por/para todos. O objetivo era por um lado fazer (re)conhecer pelos administradores as práticas de reconcepção da organização. Isso pôde ser realizado durante a pesquisa. A co-análise construtiva das práticas perdurou, facilitando as práticas reflexivas sobre o processo de pagamento do pessoal. No entanto, as interrogações mais amplas sobre a relação cliente-fornecedor entre os serviços e sobre a organização de maneira geral não pôde ser debatida no âmbito dos espaços de discussão por conta de resistências das equipes de Direção e da instabilidade da empresa (a empresa passou por um processo de fusão e o setor onde foi realizada nossa pesquisa foi recuperado por outro Grupo. Os gestores e correspondentes mudaram mais uma vez de modelo de organização).

\section{Discussão: para uma intervenção capacitante}

21 A tese é uma contribuição ao projeto da Ergonomia Construtiva e questiona mais especificamente a intervenção em ergonomia centrada no desenvolvimento. Quais seriam as características de uma intervenção capacitante onde o densenvolvimento aparece como fato, meio e finalidade da ação? O modelo clássico da intervenção (Guérin, Laville, Daniellou, Duraffourg \& Kerguelen, 2011) poderia ser completado quando a organização vira o objeto da transformação em si, além do posto ou situação de trabalho (Petit \& Coutarel, 2014). A démarche da intervenção deve desta forma simultaneamente:

- incentivar o desenvolvimento: a ênfase aqui recai sobre as condições e entraves ao desenvolvimento e os fatores de conversão de recursos em capabilidades;

- e organizar uma situação de desenvolvimento: a intervenção torna-se uma ocasião dinâmica de experimentação e de aprendizagem e as ferramentas construídas podem ser integradas na organização em si, como foi o caso aqui com o prosseguimento da co-análise construtiva das práticas. A organização se desenvolve graças à integração no seu seio de processos reflexivos abertos às capacidades de inovação dos operadores (Falzon, 2014).

A intervenção se torna um ato pedagógico (Dugué, Petit \& Daniellou, 2010) onde diferentes momentos permitem a aquisição de conhecimentos ou ainda de desenvolvimento do agir. Sua construção social deve ser pensada de tal maneira que ela possa ser uma situação de aprendizagem mútua entre o interventor, os atores e a organização. Uma das dificuldades encontradas aqui surge da impossibilidade de associar as equipes da Direção na discussão mais ampla sobre a organização. A questão da avaliação deve também ser tratada afim de verificar se a intervenção permitiu aos atores de se desenvolver, se ela aumentou suas oportunidades, se ela incentivou a adaptação da organização ou ainda se ela colocou o trabalho no centro do debate. 0 que está em jogo a curto prazo é a produção de efeitos tangíveis e intangíveis e, a longo prazo, a produção de um efeito "capacitante", ou seja, a introdução progressiva do desenvolvimento como uma das variáveis estratégicas da empresa. Esta tese tentou envolver-se sobre esta via. Ela permitiu mostrar em um plano teórico como a abordagem pelas capabilidades pode ser uma perspectiva interessante para a ergonomia e suas implicações metodológicas. A co-análise construtiva das práticas sublinhou o interesse de apoiar o diálogo entre os trabalhadores de uma mesma atividade coletiva conjunta. Os limites desse trabalho de pesquisa, em relação às dificuldades de intervenção encontradas, devem servir de ensinamentos afim de 
continuar a reflexão sobre o acompanhamento dos projetos de concepção organizacional.

\section{BIBLIOGRAFIA}

Arnoud, J. (2013). Conception organisationnelle : pour des interventions capacitantes. Thèse de doctorat en Ergonomie, Centre de Recherche sur le Travail et le Développement. Paris : Conservatoire National des Arts et Métiers.

Arnoud, J., \& Falzon, P. (2012). Shared Services Center and Work Sustainability: Which Contribution from Ergonomics? Work, 41, 3914-3919.

Arnoud, J., \& Falzon, P. (2014). Co-constructive analysis of work practices. In P. Falzon (Ed.), Constructive Ergonomics (pp. 221-236). CRC Press: Taylor \& Francis Group.

Béguin, P. (2008). Argumentos para uma abordagem dialógica da inovação. Laboreal, 4(2), 72-82. http://laboreal.up.pt/revista/artigo.php?id=37t45nSU547112341787:352:81

Daniellou F. (1999). Nouvelles formes d'organisation et santé mentale : le point de vue d'un ergonome. Archives des maladies professionnelles et de médecine du travail, 60(6), 529-533.

Detchessahar, M. (2001). Quand discuter, c'est produire... Pour une théorie de l'espace de discussion en situation de gestion. Revue Française de Gestion, 132, 32-43.

Dugué, B., Petit, J., \& Daniellou, F. (2010). L'intervention ergonomique comme acte pédagogique. PISTES, 12(3).

Falzon, P. (2014). Constructive ergonomics. CRC Press: Taylor \& Francis Group.

Guérin F., Laville, A., Daniellou, F., Duraffourg, J., \& Kerguelen, A. (2001). Compreender o trabalho para transformálo. A prática da Ergonomia. São Paulo: Edgard Blücher.

Lorino, P. (2007). Process based management and the central role of dialogical collective activity in organizational learning - the case of work safety in the building industry. International Conference on Organizational Learning, Knowledge and Capabilities (OLKC), June 14-17th, Ontario, Canada.

Petit, J., \& Coutarel, F. (2014). Interventions as dynamic processes for the joint development of agents and organizations. In P. Falzon, Constructive ergonomics (pp. 127-143). CRC Press: Taylor \& Francis Group.

Petit, J., Dugué, B., \& Daniellou, F. (2011). L'intervention ergonomique sur les risques psychosociaux dans les organisations: Enjeux théoriques et méthodologiques, Le Travail Humain, 4(74), 391-409.

Sen, A. (1997). Editorial: Human capital and human capability, World Development, 25(12), 1959-1961. 


\section{AUTOR}

\section{JUSTINE ARNOUD}

Université Paris-Est, IRG (EA 2354), UPEC, UPEM, F-94000, Créteil, France

justine.arnoud@u-pec.fr 